\title{
Correlation of p63 protein expression and Ki-67 labelling index with histological grades of meningiomas: A five years study
}

\author{
Sujani C. Madabhushi ${ }^{1{ }^{1 *} \text {, Shrinivas B. Somalwar }{ }^{2}, \text { S. Chandrasekar }{ }^{3}, \text { V. Vijay Sreedhar }}{ }^{4}$ \\ ${ }^{1}$ PG Student, ${ }^{2}$ Assistant Professor, ${ }^{3}$ Associate Professor, ${ }^{4} \mathrm{HOD}$, Upgraded Dept. of Pathology, Osmania Medical \\ College, Hyderabad, Telangana, India
}

*Corresponding Author:

Email: msujani4@gmail.com

\begin{abstract}
Introduction: Meningiomas account for $13 \%-25 \%$ of primary intracranial tumours and $\sim 25 \%$ of intraspinal tumors and histological grading has prognostic and therapeutic implications. However, histological criteria are sometimes not fulfilled to predict the biological behaviour of meningiomas, necessitating use of adjunct ancillary techniques like immunohistochemical markers. The aim of the study was to assess the correlation between the p63 protein expression with MIB-1 labelling index in different histological grades.

Materials and Methods: This was a retrospective and prospective study of patients with intracranial and intraspinal meningiomas diagnosed during the period 2009-2014. The H\& E Stained histological sections of the entire meningioma tumour were graded according to WHO 2007 criteria. Immunohistochemistry was performed using p63 protein and $\mathrm{Ki}-67$.

Result: The age of the patients ranged from 4-75 years including seven children. Out of 135 cases, 46 (34.07) cases occurred in males and the remaining $89(65.92 \%)$ cases were females. There were 125 grade I, 06 grade II, 04 grade III meningiomas. Amongst Grade I tumours $(n=125) 16 \%(n=20)$ exhibited nuclear positivity for p63 protein.

Among Grade II $(n=06)$ and Grade III $(n=04)$, all showed strong immune expression for p63. Statistical significant increase in mean labelling index (MIB1) was noted between Grade I to II and Grade II to III.

Conclusion: Increased p63 expression and Ki-67 labelling index is associated more with high grade Meningioma and possible recurrence.
\end{abstract}

Keywords: Meningiomas, MIB1 labelling index, p63 protein.

Received: $03^{\text {rd }}$ June, 2017

Accepted: $27^{\text {th }}$ September, 2017

\section{Introduction}

Meningiomas are neoplasm's derived from arachnoidal cap (Meningothelial) cells. Among primary intracranial tumors meningiomas account $13 \%-25 \%$ of the total and $25 \%$ of intraspinal tumors. Most benign meningiomas are asymptomatic and are often discovered incidentally by neuroimaging studies. Most meningiomas occur in adults between the ages of 20 to 60 years, with a peak incidence around $4^{\text {th }}$ decade of life. ${ }^{1}$ Meningiomas most likely occur in women with ratio of female to male 2:1 intracranially and 1:10 intraspinally.

Most of the meningiomas are benign (Grade I), well-circumscribed, slow-growing, and curable by surgery depending on location. ${ }^{2}$ Some meningiomas are clinically aggressive. Many, but not all, of these aggressive meningiomas fall under histological grade II (atypical) accounting between 4.7 to $7.2 \%$ and grade III (anaplastic/malignant) tumors comprising 1$2.8 \%$.The extent of tumor resection and histological grade are the two most important factors that determine the prognosis. Recurrence rate is higher in grade III meningiomas even when resected in total grossly. Inspite of total resection, propensity to recur ranges from 7$20 \%$ for benign (Grade I), $29-40 \%$ for atypical (Grade II), 50-78\% for anaplastic (Grade III). ${ }^{3}$

WHO put forth classification and grading systems for meningiomas in the year 2000 and recently updated in 2016. Predicting the behaviour using routine histological examination alone remains difficult, requiring the use of ancillary techniques like cytogenetics and immunohistochemical markers.

Many immunohistochemical markers have been suggested in the literature to aid in the diagnosis of meningiomas. Markers like Ki- $67^{1,4,5}$ p $63{ }^{6}{ }^{6}$ Claudin, ${ }^{7}$ and the absence of progesterone receptors have been mentioned in the literature. Definitive diagnosis based on using single immunohistochemical marker may be difficult at times.

To assess the growth index in various systemic and intracranial neoplasm's Ki-67 LI has been used frequently as it reflects the tumor proliferating activity. The higher the index more is the proliferative activity of the tumor. In 
meningiomas high Ki-67 LI is associated with high recurrence. Biological behavior among different grades of meningiomas can be predicted using Ki-67 LI.

p53 tumor suppressor is important in regulation of cell cycle, progression, senescence, differentiation, DNA repair and apoptosis. Two homologues, p63 and p73 belonging to p53 family have been investigated showing partial functional similarity to $\mathrm{p} 53 .{ }^{4}$ Proposed mechanisms indicate that $\mathrm{p} 63$ and p73 share some of the biological properties of $\mathrm{p} 53$, including the ability to transactivate p53responsive genes and to induce apoptosis.

Only few studies are available in the literature depicting the role of p63 expression along with $\mathrm{Ki}-67 \mathrm{LI}$ in various grades of meningiomas. In this study, we used commercially available immunohistochemical methods to detect p63 in meningiomas. We then assessed whether p63 was associated with WHO grade and the Ki-67 proliferation index as an initial step to determine its prognostic utility.

\section{Materials and Methods}

The study included excision specimen of all intracranial and intraspinal meningiomas received at the Upgraded Department of Pathology, Osmania Medical College, Hyderabad over a five year period from June, 2009 to May 2014. Clinical history, radiological images and surgical findings were collected from Neurosurgery department.

A total of 135 cases were studied over a period of five years. Study included both the left over squash and regular tumor tissue specimen. Haematoxylin-eosin stained slides of all cases were reviewed and classified according to WHO 2007.Meningiomas with brain invasion were classified as Atypical (Grade II) meningiomas. The most representative block for all 135 cases was then selected for immunohistochemical analysis by $\mathrm{p} 63$ protein and MIB-1 antibody.

Additional immunohistochemistry was performed in required cases using Epithelial membrane antigen (EMA), Glial fibrillary acidic protein (GFAP), CD31, Vimentin and S100.

\section{Immunohistochemistry Technique}

Sections measuring 4-5 $\mu \mathrm{m}$ thick were cut and taken on poly-lysine coated slides, air dried for $15 \mathrm{~min}$, heat-fixed at $42{ }^{\circ} \mathrm{C}$ and then air-dried overnight at room temperature. Next day slides were deparaffinized with xylene, and graded alcohol. Antigen retrieval was performed using pressure cooker $(125 \mathrm{C}$ for 30secs at $25 \mathrm{lbs}$ pressure). Later endogenous peroxidase activity was eliminated by treating the slides with $3 \%$ Hydrogen Peroxide for $5 \mathrm{~min}$ at room temperature. Then the slides were incubated with the diluted primary antibody (Ki67, monoclonal antibody, Dako, dilution 1;50) and p63 (clone; Dak-p63 Dako1:50), at $40{ }^{\circ} \mathrm{C}$ in a humidified chamber for $60 \mathrm{~min}$ followed by incubation in secondary antibody for $30 \mathrm{~min}$. The sections were then incubated with $\mathrm{DAB}$ for $10 \mathrm{~min}$ for visualization of the peroxidase reaction. After being washed in water for few minutes, the sections were counter stained with Harris Haematoxylin, dehydrated in alcohol, cleared in xylene and mounted in DPX.

For p63 and Ki-67 LI positive and negative controls were used for each antibody. Myoepithelial cells of the breast and basal cells of prostate were chosen as positive controls for p63 antibody labelling. For Ki-67, sections of tonsil were taken as positive control. The primary antibody was eliminated in the negative controls.1000 nuclei were counted at high magnification (40X objective) and the average was expressed as percentage. Areas showing necrosis were excluded. Reactivity of p63 stain within the nucleus of neoplastic cells was evaluated as:

Grade 0:- No staining; Grade 1+:- $<10 \%$ cells; Grade 2+:- $10-50 \%$ cells, Grade 3+:- $>50 \%$ cells.

1. 0 and + were considered negative for P63 protein expression.

2. ++ and +++ were considered positive for P63 protein expression.

For Ki-67 LI, each slide was scanned first at power (10X), and area with high density of nuclei was selected for counting at $40 \mathrm{X}$ magnification.

\section{Statistical Analysis}

Statistical calculations were carried out using SPSS version 14.1. For description of results in each group, methods of descriptive analysis such as central tendency, dispersion and frequency distribution were used as tables. The results were considered statistically significant if the $\mathrm{P}$ value was $<0.05$.

\section{Results}

We studied the immunohistochemical expression of p63 and Ki-67 LI in 135 cases of meningiomas. In the present study, the mean age for meningioma cases was 50 years (range 4-75 years), male to female ratio was 1:2. There were totally 6 children below the age of 14 years. Among the total 135 cases of Meningiomas, it was observed that intracranial location was more 
commonly involved comprising of $123(91.11 \%)$ cases followed by Intraspinal location observed in $12(8.9 \%)$ cases. The most common location of occurrence of meningiomas was frontal region comprising of total 28 cases $(20.7 \%)$ followed by parietal region which included 17 cases (12.5\%). Each one case was observed in parasagittal, petrous, tentorium cerebellum and in the third ventricle. Intraspinal meningiomas were seen in 12 cases $(8.1 \%)$.

Histological classification was done according to WHO CNS tumor classification. There were 125 Grade I (Fig. 1), 06 Grade II and
04 Grade III meningiomas. All six (6) cases included under Grade II were Atypical meningiomas as evidenced by infiltration of brain parenchyma (Fig. 2). Grade III meningiomas included three (3) papillary and one (1) anaplastic meningioma characterised by high degree of anaplasia, areas of necrosis and infiltration (Fig. 3). All the spinal tumors (12/12) in our study were Grade I. Of the 125 Grade I tumors, the Meningothelial and Transitional variants constituted the majority $25 \%$ and $18.5 \%$ respectively.

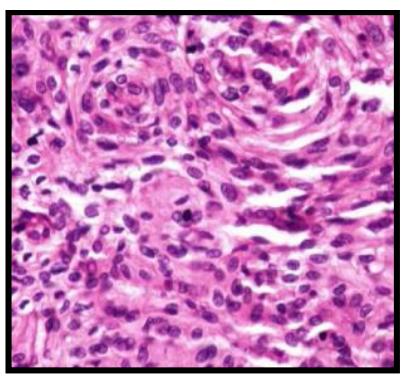

Fig. 1a: Meningothelial meningioma showing whorls of Tumor cells (H\& E) (40X)

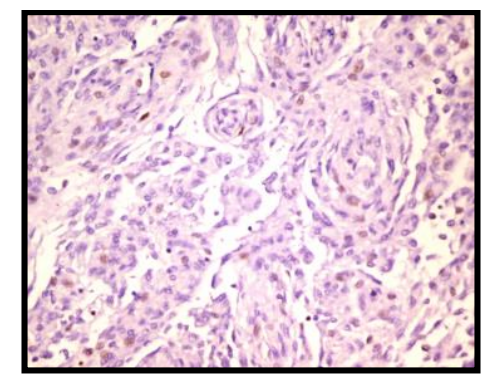

Fig.1b: Low Ki-67 index (40X)

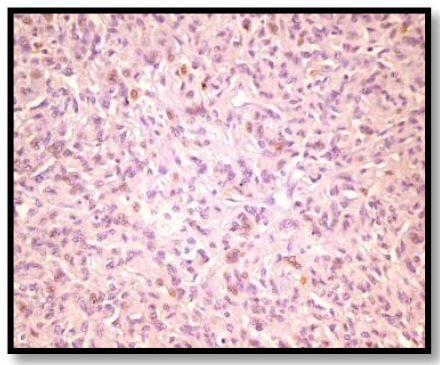

Fig. 1c: p63 immunopositivity in $<10 \%$ of tumor cells $(40 \mathrm{X})$

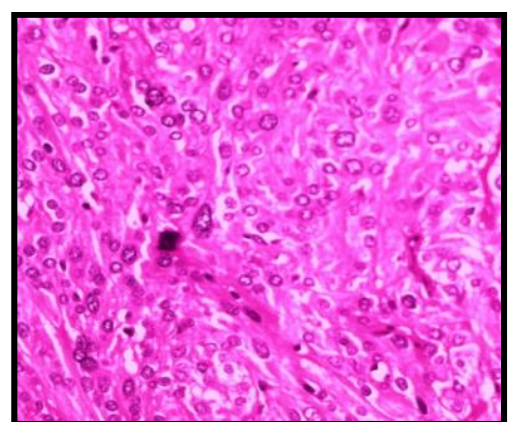

Fig. 2a: Tumor cells showing Atypical mitotic figure ( Arrow) (H\&E) 40X

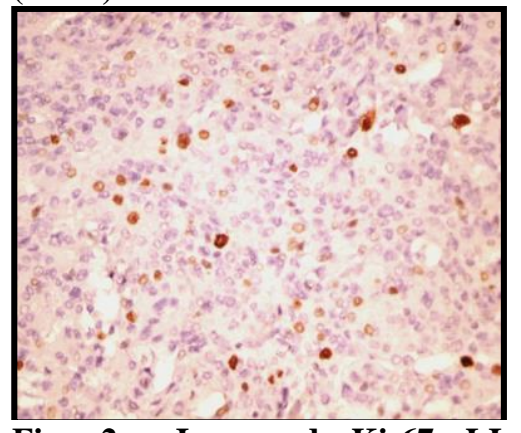

Fig. 2c: Increased Ki-67 LI (40X)

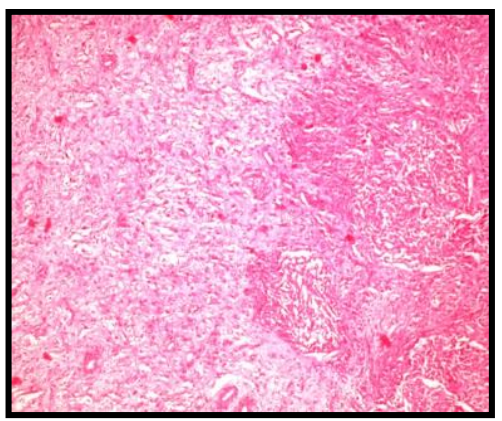

Fig. 2b: Brain Invasion in atypical meningioma (H\&E) 40X

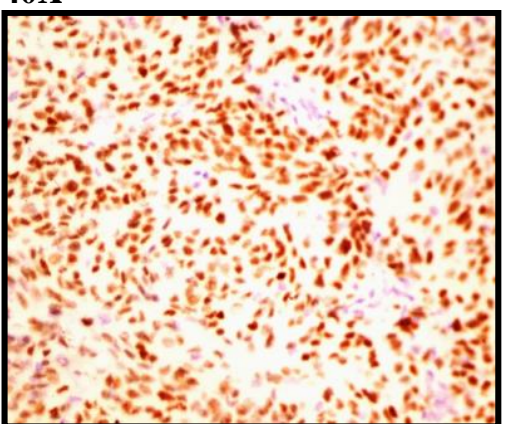

Fig. 2d: Immunopositivity in $>50 \%$ of tumor cells $(\mathbf{4 0 x})$

Fig. 2: Atypical meningioma 


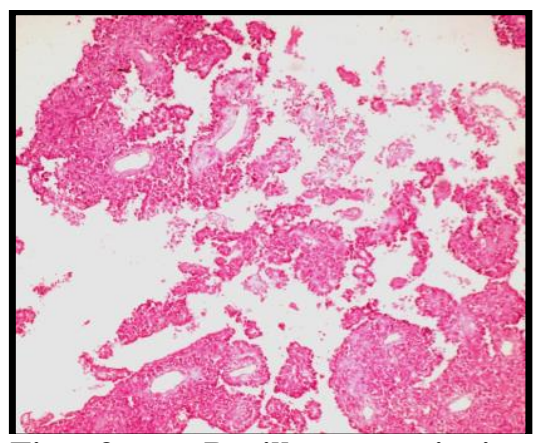

Fig. 3 a: Papillary meningioma showing tumor cells arrranged in papillary configuration $(\mathrm{H} \& \mathrm{E} 10 \mathrm{X})$

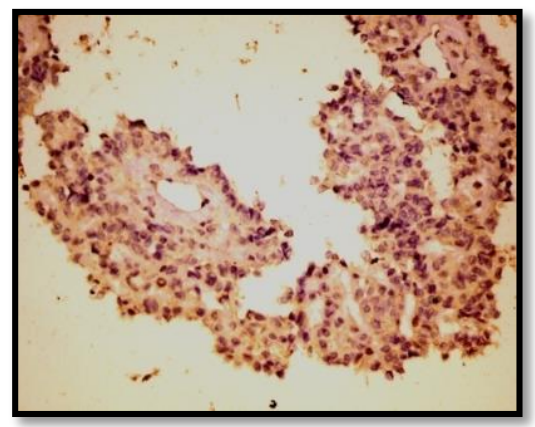

Fig. 3 c: Moderate Ki-67 $\mathrm{LI}$ in papillary Meningioma 40X

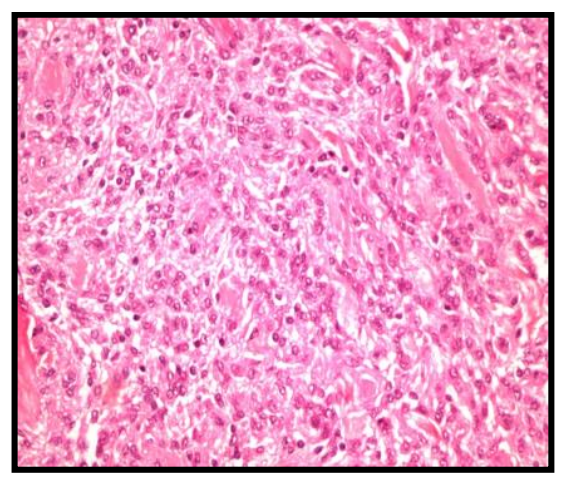

Fig. 4 a: Tumor cells with Increased cellularity

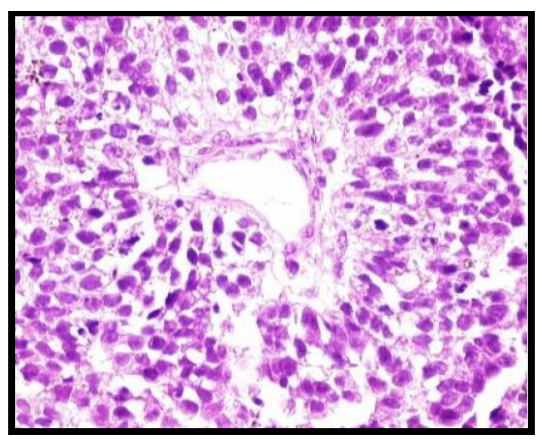

Fig. 3b: Papillary meningioma showing pleomorphic cells formig perivacualar pseudorosettes (H\&E) 40X

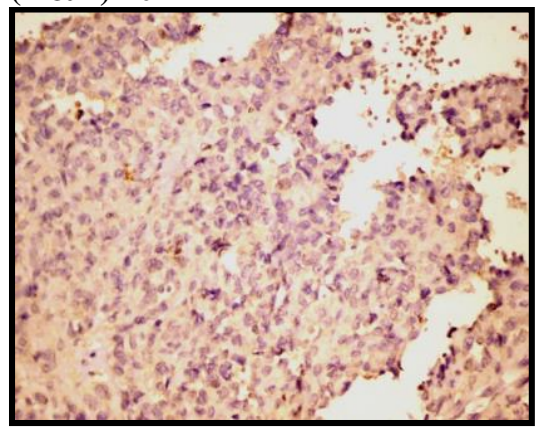

Fig. 3 d: p63 immunoexpression in $>10-<50 \%$ of tumor cells in papillary meningioma $40 \mathrm{X}$

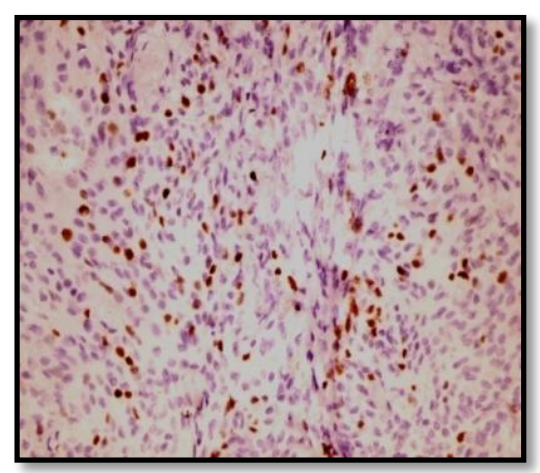

Fig.4 b: Increased Ki-67 LI (40X)

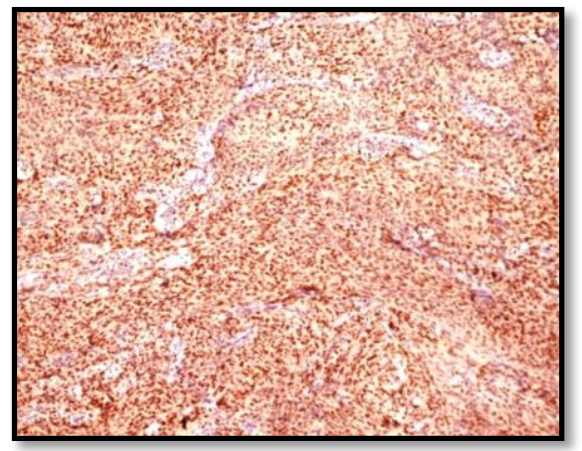

Fig.4 c: p63 immunopositivity in $>50 \%$ of tumor cells $(40 \mathrm{X})$ 


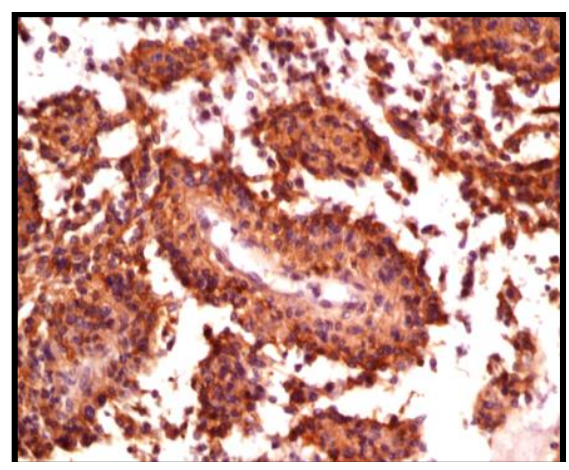

Fig. 5a: Strong EMA expression $40 \mathrm{X}$

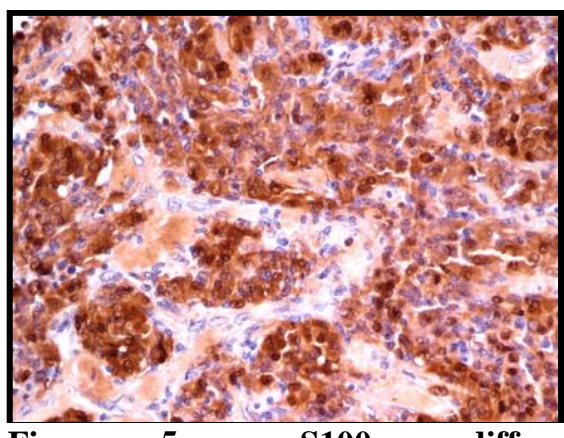

Fig. $5 c:$ S100 diffuse immunoexpression $40 \mathrm{X}$

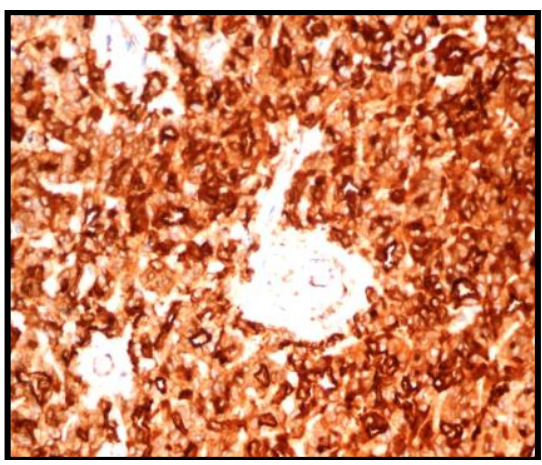

Fig. 5b: Strong vimentin expression 40X

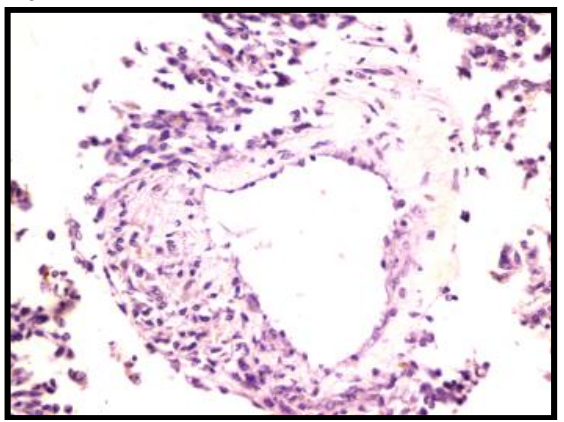

Fig. 5d: GFAP immunonegative (40 X)

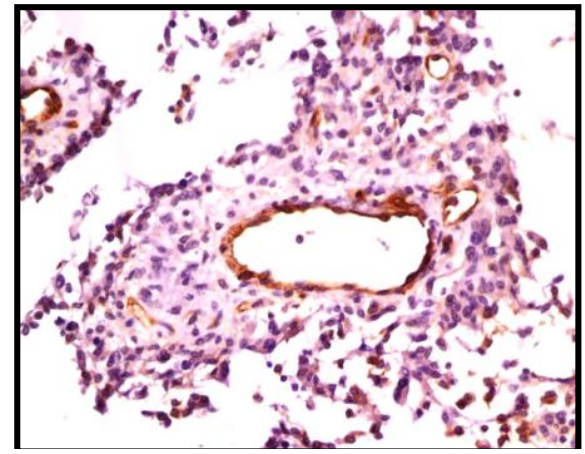

Fig. 5e: CD31 Highlighting the endothelial Cells of Papillary cores in Papillary meningioma (40X)

In our study p63 and Ki-67 LI did not show statistical significance with respect to age and gender. Among grade I tumors Meningothelial variant expressed high p63 (mean=3.212) expression and Ki-67 LI (mean = 3.212) $($ Fig. 4) followed by transitional (mean p63= 7.08, Ki-67 LI= 1.421), fibroblastic (mean p63 $=0.36 \mathrm{Ki}-67 \mathrm{LI}=0.569$ ), psammomatous (mean p63 $=0.54$, Ki-67 LI= 0.821), angiomatous (mean p63 = 0, Ki-67 LI= 0.608), and metaplastic (mean p63=1, Ki-67 LI= 0.7). (Table 1)

Table 1: Correlation of P63 and Ki67 with respect to Age, Sex, Histological grade and morphological subtypes

\begin{tabular}{|c|c|c|c|c|c|c|c|}
\hline & $\mathbf{N}$ & \multicolumn{2}{|c|}{ Mean } & \multicolumn{2}{c|}{ SD } & \multicolumn{2}{c|}{ Standard Error } \\
\hline Age & & $\mathbf{p 6 3}$ & $\mathbf{K i}-67$ & $\mathbf{p 6 3}$ & $\mathbf{K i - 6 7}$ & $\mathbf{p 6 3}$ & Ki-67 \\
\hline 1-10yrs & 03 & 0.0 & 0.6 & 0.0 & 0.0 & 0.0 & NA \\
\hline $11-20 \mathrm{yrs}$ & 05 & 10.72 & 1.8 & 21.36 & 1.43 & 8.721 & NA \\
\hline $21-30 \mathrm{yrs}$ & 10 & 4.76 & 1.37 & 11.79 & $\ddots$ & 3.151 & NA \\
\hline $31-40 \mathrm{yrs}$ & 24 & 7.94 & 1.43 & 17.77 & 1.85 & 3.094 & NA \\
\hline $41-50 \mathrm{yrs}$ & 47 & 7.66 & 1.59 & 16.99 & 1.8 & 2.505 & NA \\
\hline $51-60 \mathrm{yrs}$ & 23 & 12.5 & 1.725 & 25.53 & 2.11 & 6.383 & NA \\
\hline
\end{tabular}




\begin{tabular}{|c|c|c|c|c|c|c|c|}
\hline 61-70yrs & 15 & 8.88 & 1.65 & 16.53 & 1.64 & 5.848 & NA \\
\hline $71-80 y r s$ & 08 & 0.0 & 1.4 & 0.0 & 0.0 & 0.0 & NA \\
\hline Total & 135 & 8.13 & NA & 17.85 & NA & 1.597 & NA \\
\hline Sex & & & & & & & \\
\hline Males & 46 & 6.82 & 1.495 & 17.06 & 1.837 & 2.698 & NA \\
\hline Females & 89 & 8.74 & 1.55 & 18.282 & 1.720 & 1.983 & NA \\
\hline $\begin{array}{c}\text { Histological } \\
\text { Subtypes } \\
\text { Grade 1 }\end{array}$ & & & & & & & \\
\hline Meningothelial & 34 & 23.06 & 3.212 & 25.07 & 2.34 & 4.364 & 0.417 \\
\hline Fibroblastic & 25 & 0.36 & 0.569 & 0.903 & 0.47 & 0.177 & 0.09 \\
\hline Transitional & 33 & 7.08 & 1.421 & 16.23 & 1.172 & 2.825 & 0.204 \\
\hline Psammomatous & 20 & 0.54 & 0.821 & 1.168 & 0.510 & 0.268 & 0.0 \\
\hline Angiomatous & 11 & 0.0 & 0.608 & 0.0 & 0.483 & 0.0 & 0.139 \\
\hline Metaplastic & 02 & 1.0 & 0.7 & 1.414 & 0.701 & 1.0 & 0.5 \\
\hline $\begin{array}{c}\text { Grade 2 } \\
\text { Atypical }\end{array}$ & 06 & 92.83 & 7.7 & 4.62 & 0.983 & 21.366 & 0.897 \\
\hline $\begin{array}{c}\text { Grade 3 } \\
\text { Papillary }\end{array}$ & 03 & 22.33 & 2.37 & 13.79 & 0.750 & 190.33 & 0.568 \\
\hline Anaplastic & 01 & 97.6 & 12.8 & NA & NA & NA & NA \\
\hline Total & 135 & 8.13 & 1.53 & 17.86 & 1.751 & 1.6 & 0.156 \\
\hline
\end{tabular}

Statistical Test - Independent t -test, p63 expression (p value for age- 0.960 , not significant statistically; $p$ value for sex- 0.56 , not significant ); Ki-67 LI( $p$ value for age- 0.99 not significant ; $p$ value for sex -0.858 ,not significant)

All 6 grades II tumors expressed 3+ positivity for p63 expression accounting to a mean of 92.8 and among grade III anaplastic variant was showing highest p63 protein expression with mean of 97.16. (Table 2)

Table 2: p63 Immunoreactivity According to Histological Grade

\begin{tabular}{|l|c|c|c|}
\hline $\begin{array}{c}\text { P63 } \\
\text { Immunoreactivity }\end{array}$ & $\begin{array}{c}\text { Grade I } \\
(\mathbf{n = 1 2 5})\end{array}$ & $\begin{array}{c}\text { Grade II } \\
(\mathbf{n = 0 6})\end{array}$ & $\begin{array}{c}\text { Grade III } \\
(\mathbf{n = 0 4 )}\end{array}$ \\
\hline Negative & $62 \%$ & 00 & 00 \\
\hline$+(10 \%)$ positivity & $22 \%$ & 00 & 00 \\
\hline$++(10-50 \%)$ & $10 \%$ & 00 & $75 \%$ \\
\hline$+++(>50 \%)$ & $06 \%$ & $100 \%$ & $25 \%$ \\
\hline Total & $100 \%$ & $100 \%$ & $100 \%$ \\
\hline
\end{tabular}

Out of the total 135 cases in this study, 4 cases (2.2\%) had recurrence as documented by computed tomography (CT) and or MRI of brain. Out of the 4 recurrent cases, 3 cases were Grade I meningioma, 1 case was atypical variant in 49 years male. The previous reported sections of the recurrent cases were analyzed and one representative block was selected from each case and was stained for immunoreactivity with p63.Out of the 4 documented recurrent cases, 3 cases (grade 1) showed immunoreactivity of $2+$ and the case with atypical variant (grade II) showed positivity of $3+$.

In a case of papillary meningioma in 8 years female child, we had a differential diagnosis of papillary ependymoma, immunohistochemistry with EMA, GFAP, Vimentin, CD31 and S100 was performed. (Fig.5)

\section{Discussion}

Most of the Meningiomas are benign and more frequently occur in elderly and middle aged patients. There are several reports available in the literature proposing the impact of age and gender on the proliferative activity and recurrence of meningiomas.

Ilidian et al, ${ }^{9}$ reported that age and gender has no influence on proliferative activity. Kasuya et $\mathrm{a}^{10}$ reported that male gender was an independent risk factor for high proliferative potential. The mean Ki$67 \mathrm{LI}$ and p63 with respect to age and gender was not statistically significant in our series. 
Definitive diagnosis of meningiomas is based on histopathological study, but there are limitations associated with the standard histology. Recurrence in some meningiomas has been noted with no known aggressive parameters. Concern is meningiomas those which are morphologically benign but aggressive biologically.

Several immunohistochemical biomarkers have been suggested to aid Conventional methods. Previous studies have shown many indicators for prediction of behaviour of meningiomas such as proliferative markers Ki67, ER, PR, AgNOR and expression of p53, p73 and p63.

There are only very few studies available in the indexed literature that correlates p63 expression with overall histological grade of the meningioma.

Table 3

\begin{tabular}{|l|c|c|c|c|c|}
\hline \multicolumn{1}{|c|}{ Grades } & \multicolumn{2}{|c|}{$\begin{array}{c}\text { Elisabeth J Rushing } \\
\text { et al (2008) } \\
\mathbf{n = 3 7}\end{array}$} & $\begin{array}{c}\text { Nourieh } \\
\text { Sharifi et } \\
\text { al (2008) } \\
\mathbf{n = 5 2}\end{array}$ & $\begin{array}{c}\text { Deepali } \\
\text { Jain et al } \\
\mathbf{( 2 0 1 2 )}^{\mathbf{1 3}} \\
\mathbf{n = 8 5}\end{array}$ & $\begin{array}{c}\text { Present } \\
\text { Study (2014) } \\
\mathbf{n = 1 3 5}\end{array}$ \\
\hline & Nuclear & Cytoplasmic & & & \\
\hline Grade I & $05 \%$ & $00 \%$ & $83.20 \%$ & $34.90 \%$ & $16 \%$ \\
\hline Grade II & $92 \%$ & $31 \%$ & $100 \%$ & $63.60 \%$ & $100 \%$ \\
\hline Grade III & $75 \%$ & $100 \%$ & $100 \%$ & $63.60 \%$ & $100 \%$ \\
\hline p value & $<0.001$ & $<0.001$ & 0.001 & 0.002 & 0.001 \\
\hline
\end{tabular}

In the present study we found that $16 \%$ of Grade I meningiomas exhibited nuclear positivity for $\mathrm{p} 63$. Among Grade II meningiomas which included the Atypical variant $(n=06)$, all the cases showed high p63 nuclear reactivity of more than 3+. Among Grade III meningiomas three were papillary and one was anaplastic. In anaplastic variant, more than 3+ immunopositivity for p63 was recorded but papillary meningiomas exhibited varied expression ranging from $1+$ to $3+$.

In our study correlation was established between expression of p63 protein with $\mathrm{Ki}-67$ LI. In Grade I meningiomas the mean \pm SD MIB index was $1.53 \pm 1.75$ and in Grade II it was $7.66 \pm 0.98$ and in Grade III 4.97 \pm 5.25 .

There was a correlation between the values of Ki-67 LI and the histological grades although Ki-67 LI was of different values in different series according to the gradual differences among series. Grade III meningiomas were higher than the other grade I and grade II meningiomas in other studies. But in our study Grade III meningiomas exhibited low MIB-1 Labelling Index.

In our present study we found the p63 immunoreactivity and the $\mathrm{Ki}-67$ proliferation index low in Grade III Papillary meningiomas $(n=3)$. In a case of papillary meningioma in 8 years female child, we had a differential diagnosis of papillary ependymoma.

Immunohistochemistry with EMA, GFAP, and S100 was performed. EMA showed intense cytoplasmic and membrane staining, GFAP dint show any expression, S100 showed diffuse positivity, confirming the diagnosis of Papillary meningioma. In another case of 8 years female child Hemangiopericytoma was suspected, immunohistochemistry with EMA, GFAP, CD31 and S100 was performed.

EMA showed intense cytoplasmic and membrane staining, CD31, S100, GFAP were negative, thus making the diagnosis of meningioma. Thus Diagnostic confusion with choroid plexus papillomas, papillary ependymoma and metastatic papillary adenocarcinoma were ruled out in the respective cases.

Rushing et al ${ }^{14}$ reported that the MIB-1 LI of atypical meningiomas ranged from 3-19\%, mean $12 \%$, and from $5.5-17.5 \%$, mean $11.75 \%$ for papillary meningioma. We could not find any conflicting reports suggesting the cause for low p63 expression in the literature.

Given the small number of cases in Grade II and III meningiomas in the present study, additional implication with respect to proliferative activity needs to be elucidated. Though the extent of resection, grade and type of meningiomas are important consideration, recurrence has been noted in some meningiomas with no known aggressive parameters. As many as $7 \%-20 \%$ of benign (WHO Grade I) meningiomas are known to recur.

In our study 20 cases of grade I meningiomas displayed high p63expression and Ki-67 LI, which was also observed by Guarnaschelli et $\mathrm{al}^{15}$ of which 4 presented with recurrence. Patient's age ranged from 25-55 years in the recurrent group, with female to male 
ratio of 1:3. Mortality among patients with tumor recurrence was $1 / 4(25 \%)$. Out of 4 recurrent cases 3 cases were classified as WHO grade I histologically which showed no features of atypia and brain invasion; however these cases showed focal hyper cellular areas.

The other one case of recurrence was histologically Grade II with features of nuclear atypia, pleomorphism, increased mitotic count and areas of necrosis. All the four recurrent cases were intracranial in location and the male to female ratio was $3: 1$.The number of recurrent tumors in the present study was small, hence we could not correlate between p63 expression with Ki-67 LI. Rest 16 of WHO grade 1 meningioma cases with high Ki-67 LI with corresponding high p63 expression are under follow-up. The mean Ki-67 LI and p63 expression of recurrent meningiomas were $8.6 \%$ and $62.5 \%$ respectively. Period of recurrence ranged between 2.1 and 9.5 years with a mean of 6 years. Among the recurrent tumors the $\mathrm{p}$ value for Ki-67 and p63 were highly significant $0.0043,0.0009$ respectively. The expression of p63 when correlated with that of Ki-67 LI retrospectively was statistically significant.

One case of recurrence was observed in a $49 y$ rs old male patient who presented with a left frontoparietal SOL with a mean recurrence of 2.1 yrs. The Ki-67 index was 9.6 and p63 expression was +3 .

Several studies have reported higher recurrence rates for males than for females. ${ }^{16-19}$ However other studies, have found no significant difference based on gender.1, ${ }^{18,19}$ Nakasu et al ${ }^{20}$ and several other authors found no association between tumor development in young patients $(<40 \mathrm{yrs})$ and a high likelihood of recurrence. ${ }^{20}$ However, Perry and associates ${ }^{21}$ found a significant difference between age and recurrence, while Adegbite and associates ${ }^{22}$ could demonstrate no significant influence of sex and age on recurrence.

\section{Conclusion}

In the present study increased p63 expression and Ki-67 LI is associated more with high grade meningioma and possible recurrence. No Significant Correlation was found for Age, Sex, and Location with respect to Histological grades of Meningiomas in our study. The present study although it demonstrates statistically significant difference in p63 expression and Ki67 LI between benign and high grade tumors, may not be taken as discriminating markers on practical grounds. The present study is limited by short follow -up in 20 patients following under grade 1 with increased p63 and Ki-67 expression.

\section{References}

1. Kasuya H, Kubo O, Tanaka M, Amano K, Kato $\mathrm{K}$, Hori T. Clinical and radiological features related to the growth potential of meningioma. Neurosurg Rev 2006;29:293-7.

2. Louis DN, Scheithauer BW, Budka H, Von Deimling A, Kepes JJ, Meningiomas. Kleihues P, Cavenee WK: World Health Organization Classification of Tumours. Pathology and Genetics of Tumours of the Nervous System Lyon, IARC Press, 2000;176-84.

3. Karamitopoulou E, Perentes E, Melachrinou M, et al Proliferating cell nuclear antigen immunoreactivity in human central nervous system neoplasms. Acta Neuropathol 85:316-322, 1993

4. Hopf NJ, Bremm J, Bohl J, Perneczky A. Image analysis of proliferating cells in tumors of the human nervous system: an immunohistological study with monoclonal Antibody Ki67. Neurosurg 1994; 35:917-23

5. LoMuzio L, Campisi G, Farina A. Effect of p63 expression on survival in oral squamous cell carcinoma. Cancer Invest. 2007;25:466-9.

6. Sharifi N, Katebi M. An immunohistochemical study of p63 protein expression in meningioma. Iranian J Pathol 2008;3:146-50.

7. Hahn HP, Bundock EA, Hornick JL Immunohistochemical staining for claudin- 1 can help distinguish meningiomas from histologic mimics. Am J Clin Pathol. 2006 Feb;125(2):203-8

8. Nakasu S, Nakasu Y, Nakajima M, Matsuda M, Handa J. Preoperative identification of meningiomas that are highly likely to recur. J Neurosurg 1999;90:455-62

9. Ildan F, Erman T, Göçer AI, Tuna M, Bağdatoğlu H, Cetinalp E, Burgut R,et al. Predicting the Probability of Meningioma Recurrence in the Preoperative and Early Postoperative Period: A Multivariate Analysis in the Midterm Follow-Up. Skull Base, 2007 may;17(3):157-72.

10. Kasuya H, Kubo O, Tanaka M, Amano K, Kato K, Hori T. Clinical and Radiological features related to growth potential of meningioma. Neurosurg Rev, 2006;29:293-7

11. Rushing E J, Oslen C, Man YG. Correlation of p63 immunoreactivity with tumor grade in Meningiomas. Int J surg pathol, 2008;16:38-42.

12. Sharifi.N, Katebi.M.An immunohistochemical study of p63 protein expression in Meningioma. Iranian J of pathol, 2008; Mar(3):146-50.

13. Mittal.S, Jain.D, Roy.S, Singh V. Correlation of p63 protein expression with histological grade of meningioma:An immunohistochemical study . Int J surg pathol , 2012;20(4):349- 54.

14. Kolles H., Niedermayer I., Schmitt CH. et al. Triple approach for diagnosis and grading of meningiomas:Histology, morphologyof Ki-67 and cytogenetics. J. Acta Neuro chirurgica, 2005;137:174-81.

15. Guarnaschelli JJ, Stawicki SP. Brief communication: Recurrent brain meningiomas. OPUS 12 Scientist 2008; 2:32-4. 
16. Boldrey E. In: Minckler J, editor. Pathology of the Nervous System. New York, NY:McGraw-Hill; 1971. The meningiomas. pp. 2125-44.

17. Gupta P K, Sastry Kolluri V R, Das S, Chandra Mouli B A, Narayana Swamy K S, Das B S.

Recurrences in meningioma after surgery. Acta Neurochir (Wien), 1989;100:104-7.

18. Mahmood A, Qureshi N H, Malik G M. Intracranial meningiomas: analysis of recurrence after surgical treatment. Acta Neurochir (Wien), 1994;126:53-8.

19. Perry A, Stafford S L, Scheithauer B W, Suman V J, Lohse C M. Meningioma grading:An analysis of histologic parameters. Am J Surg Pathol, 1997;21:1455-65.

20. Nakasu S, Nakasu Y, Nakajima M, Matsuda M, Handa J. Preoperative identification of meningiomas that are highly likely to recur. $\mathrm{J}$ Neurosurg, 1999;90:455-62.

21. Perry A, Stafford S L, Scheithauer B W, Suman V J, Lohse C M. Meningioma grading: an analysis of histologic parameters . Am J Surg Pathol, 1997;21:1455-65.

22. Adegbite A B, Khan M I, Paine K WE, Tan L K. The recurrence of Intracranial meningiomas after surgical treatment. J Neurosurg, 1983;58:51-6. 